\title{
Preservation of the smooth muscular internal (vesical) sphincter and of the proximal urethra during retropubic radical prostatectomy: A technical modification to improve the early recovery of continence
}

\author{
Eugenio Brunocilla, Riccardo Schiavina, Marco Borghesi, Cristian Pultrone, Matteo Cevenini, \\ Valerio Vagnoni, Giuseppe Martorana \\ University of Bologna - S. Orsola-Malpighi Hospital, Bologna, Italy.
}

\begin{abstract}
Summary Objective: We describe our technique for preservation of the smooth muscular internal (vesical) sphincter and proximal urethra during radical retropubic prostatectomy (RRP) and present our preliminary clinical results.

Materials and methods: The first steps of the prostatectomy reflect the standard RRP, while for the final phases the procedure continues in an anterograde manner with incision of the fibers of the detrusor muscle at the insertion of the ventral surface of the base of the prostate. At this level, the inner circular muscle of the bladder neck forms a sphincteric ring of smooth muscle that covers the longitudinally oriented smooth muscle component of the urethral musculature that extends distally to the verumontanum. These two proximal structures represent the internal sphincter that envelops and locks the proximal urethra. A blunt dissection is continued until the ring shaped vesical sphincter is separated from the prostate and the longitudinally oriented smooth muscle component of the urethral musculature is identified. The base of the prostate is then gently separated from the urethra and from the bladder until the maximal length of the urethral musculature is isolated and preserved.

Results: After 30 initial set-up procedures, 40 consecutive patients with organ confined prostate cancer were submitted to radical retropubic prostatectomy with the preservation of muscular internal sphincter and the proximal urethra and compared to 40 patients submitted to standard procedure who served as control group. The group of patients submitted to our technical modification had a faster recovery of early continence than control group at 3 and 7 days.

Conclusions: The described technique is a feasible and safe method for preservation of the internal urethral sphincter and allows improving the early recovery of urinary continence. The technique does not increase the rate of positive margins and the duration of the procedure.
\end{abstract}

KEY WORDS: Radical prostatectomy; Urinary continence; Internal sphincter; Proximal urethra; Surgical margins.

Submitted 9 September 2013; Accepted 31 March 2014

\section{INTRODUCTION}

Retropubic radical prostatectomy (RRP) is one of the standard surgical methods for the treatment of clinically localised prostate cancer $(\mathrm{PCa})$. The preservation of urinary continence is one of the most important endpoints of the procedure. Numerous mechanisms have been advocated as responsible for male postoperative urinary continence but the preservation of the integrity of the external urethral sphincter muscle, of the pelvic floor as well as anterior and posterior urethral support seem to play the most important role (1). Young age and nervesparing procedure have been proposed as additional protective factors (2). During the last few decades, many technical modifications have been described in order to improve clinical results (3-6). In particular, the Rocco stitch has shown an important potential role for the early recovery of continence $(5,6)$. In this paper, we describe our approach of preservation of the smooth muscular internal (vesical) sphincter (MIS) as well as of the proximal urethra (PA) during bladder neck dissection as part of the conservation of the full functional length of the urinary sphincter and we present our preliminary results.

\section{Materials AND METHOdS}

Anatomic considerations and surgical technique

The first part of the procedure is similar to the standard RRP described by Walsh and co-workers (7) concerning the maintenance of the anterior and posterior urethral supports. in all cases we preserve the pubourethral and puboprostatic ligaments and we reconstruct the posterior musculofascial plate as described by Rocco (6); great attention is made in preserving the integrity of the external urethral sphincter muscle, with clear visualization of the circular orientated horseshoe-shaped urethral sphincter (with its striated and smooth components, the rabdomyosphincter) and with the preservation of the maximal part of the longitudinally oriented smooth muscle of the urethra (the intrinsic sphincter or lissosphincter) that is close to the urethral lumen.

No conflict of interest declared. 
In the second part of the prostatectomy, the procedure becomes antegrade, with the aim of preserving the internal vesical sphincter and the PA. We cut the fibers of the detrusor muscle at the insertion of the ventral aspect of the base of the prostate; at this level, the inner circular smooth muscle of the bladder neck forms a sphincteric ring of smooth muscle that extend distally to the verumontanum and covers the longitudinally oriented smooth muscle component of the urethral musculature (the cranial prolongation of the lissosphincter). These structures represent the internal (vesical) sphincter that covers the PA (Figure 1). Presence of nodules of benign prostatic hyperplasia within the wall of the internal sphincter, previous surgery for benign prostatic obstruction (BPO) as well as loss of the integrity of the circular smooth muscle during radical prostatectomy may impair the function of the internal sphincter. A blunt dissection is continued till the ring shaped vesical sphincter is separated from the prostate and the longitudinally-oriented smooth muscle component of the urethral musculature is identified. Thus, the base of the prostate is gently separated from the urethra till the maximal length of the internal (vesical) sphincter is preserved and the urethra is incised to remove the catheter. Finally, the anastomotic sutures are placed through the distal urethral stump of external sphincter and the PA structure and are fixed to the circular fibers of the bladder neck. To assess the oncologic safety of our surgical technique, we perform circumferential biopsies of the PA and of the base of the prostate during the dissection in all cases.

\section{Case-control study}

After 30 initial set-up procedures, we performed a prospective case-control study to assess the impact of our technique on urinary continence $(8,9): 40$ consecutive patients with organ confined PCa were submitted to radical retropubic prostatectomy with the preservation of muscular internal sphincter (MIS) and the PA and compared to 40 patients submitted to standard procedure who served as control group. Exclusion criteria were large mid lobe prostate or large prostate volume $(>80 \mathrm{cc}$ ) and high-risk $\mathrm{PCa}$ (defined as PSA > $20 \mathrm{ng} / \mathrm{ml}$ or clinical T3 or clinical Gleason score > 7). The same surgeon with 25 years experience in RRP performed all surgical procedures. In all cases the catheter was removed after 12 days.

Continence rates were assessed using a self-administrated questionnaire at 3, 7, 30 days and 3, 12 months after removal of the catheter.

\section{Results}

The group of patients submitted to our technical modification had a faster recovery of early continence than control group at 3 days ( $45 \%$ vs. $22 \% ; p=0.029$ ) and at 7 days ( $75 \%$ vs. $50 \%$; $\mathrm{p}=0.018$ ); considering the number of pads, group 1 had faster recovery of continence at 3, 7 and 30 days and a minor incidence of severe incontinence.
Figure 1.

ification and isolation of about $10 \mathrm{~mm}$ of proximal urethra during neck, with the preservation of the internal vesical sphincter.

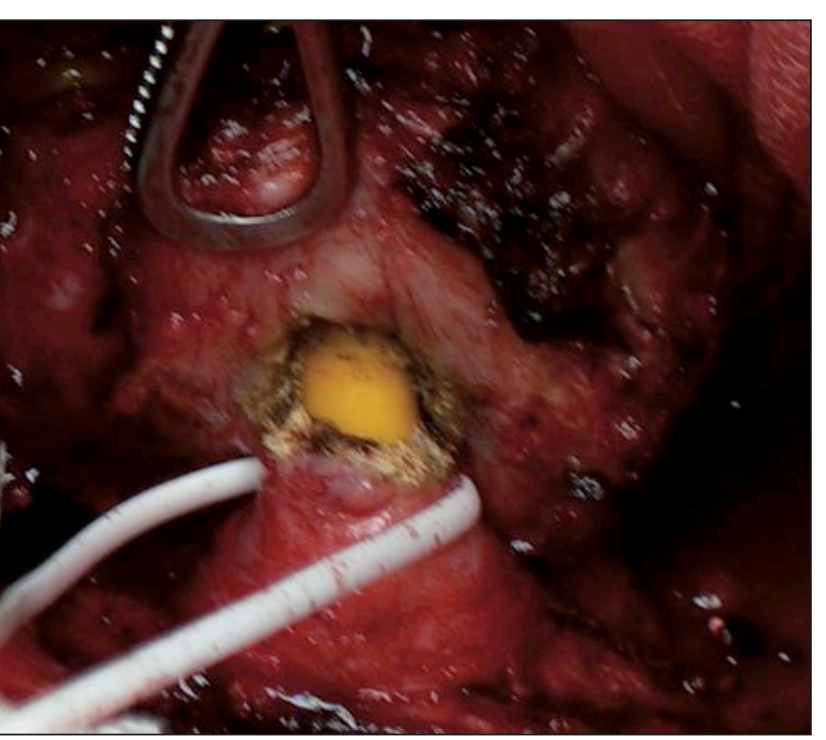

There were no statistically difference in terms of continence at 3 and 12 months among the two groups. Multivariate logistic regression analysis of continence in relation to the clinical, pathological and surgical characteristics showed that surgical technique and young age were significantly associated with earlier time to continence at 3 and 7 days, while there were no significant correlations with continence at 30 days, 3 and 12 months. The two groups had no significant differences in terms of positive surgical margins. There were no cases of bladder neck sclerosis/stricture or acute urinary retention.

\section{Discussion}

Recently others authors described the first clinical trial with the same technique, with optimal results in terms of early recovery of the continence (10). They demonstrated significantly lower urine loss, higher objective and social continence rates and higher QoL-scores in patients who underwent this technique, thus confirming the positive impact of this technique in urinary incontinence after radical prostatectomy.

\section{Conclusion}

In conclusion, in well-selected patients, our modified technique may accelerate the recovery of urinary continence and may improve the continence when the rabdosphincter has not been perfectly preserved. No additional positive margins were noted in both the two clinical trials and we look forward for the follow-up data to confirm its oncological safety. Our preliminary results show optimal rates of recovery of urinary continence after surgery. However, because of the small number of patients who underwent this technique, further evaluation and comparative studies are needed to confirm these encouraging initial results. 


\section{References}

1. Xylinas E, Ploussard G, Durand X, et al. Evaluation of combined oncological and functional outcomes after radical prostatectomy: trifecta rate of achieving continence, potency and cancer control - a Literature review. Urology. 2010; 76:1194-8.

2. Walz J, Burnett AL, Costello AJ, et al. A critical analysis of the current knowledge of surgical anatomy related to optimization of cancer control and preservation of continence and erection in candidates for radical prostatectomy. Eur Urol. 2010; 57:179-92.

3. Licht MR, Klein EA, Tuason L, et al. Impact of bladder neck preservation during radical prostatectomy on continence and cancer control. Urology. 1994; 44:883-7.

4. Schlomm T, Heinzer H, Steuber T, et al. Full functional-length urethral sphincter preservation during radical prostatectomy. Eur Urol. 2011; 60:320-9.

5. Rocco F, Carmignani L, Acquati P, et al. Restoration of posterior aspect of rhabdosphincter shortens continence time after radical retropubic prostatectomy. J Urol 2006; 175:2201-6.

6. Gautam G, Rocco B, Patel VR, et al. Posterior rhabdosphincter reconstruction during robot-assisted radical prostatectomy: critical analysis of techniques and outcomes. Urology. 2010; 76:734-41.

7. Walsh PC, Lepor H, Eggleston JC, et al. Radical prostatectomy with preservation of sexual function: anatomical and pathological considerations. Prostate. 1983; 4:473-85.

8. Brunocilla E, Pultrone C, Pernetti R, et al. Preservation of the smooth muscular internal (vesical) sphincter and of the proximal urethra during retropubic radical prostatectomy: Description of the technique. Int J Urol. 2012; 19:783-5.

9. Brunocilla E, Schiavina R, Pultrone CV, et al. Preservation of the smooth muscular internal (vesical) sphincter and of the proximal urethra for the early recovery of urinary continence after retropubic radical prostatectomy: A prospective case-control study. Int J Urol. 2013 Jun 26.

10. Nyarangi-Dix JN, Radtke JP, Hadaschik B, et al. Impact of complete bladder-neck preservation on urinary continence, quality of life and surgical margins after radical prostatectomy: a randomised controlled single-blind trial. J Urol. Published on line: 24 Sep 2012.

\section{Correspondence}

Eugenio Brunocilla, MD

Riccardo Schiavina, MD (Corresponding Author)

rschiavina@yahoo.it

Marco Borghesi, MD

Cristian Pultrone, MD

Matteo Cevenini, MD

Valerio Vagnoni, MD

Giuseppe Martorana, MD

University of Bologna - S. Orsola-Malpighi Hospital, Bologna,

Via Palagi 9 - 40134 Bologna, Italy 